\title{
Research on the Effective Supply Strategy of Natural Gas based on Factor Analysis Method
}

\author{
Guang-jing $\mathrm{He}^{1}$ Rong-ge Xiao ${ }^{1}$ and Yu-heng Zhang ${ }^{2}$ \\ ${ }^{1}$ School of Earth Sciences and Resources,China University of Geosciences, Beijing, 100000, China \\ ${ }^{2}$ School of Land Science and Technology, China University of Geosciences, Beijing, 100000,China
}

Keywords: natural gas; effective supply; factor analysis method

\begin{abstract}
As China's economic growth and social development, energy demand is increasing. As an efficient and clean energy, natural gas is widely used in various fields such as industry and agriculture. However, the contradiction between demand increase of natural gas and limited resources has become increasingly intensified, which restricts China's economic development. So it is important to improve the effective supply. The paper firstly summarizes the factors affecting effective supply of natural gas; secondly, gets the combined effect factors by using factor analysis method of SPSS and analyzes the importance of each factor; finally, based on the estimation of effective supply of natural gas, the effective suggestions are proposed.
\end{abstract}

\section{Introduction}

Energy, as an indispensable resource for economic development, social progress, human survival, has a crucial role for China's development [1]. With the constant exploitation of coal and oil, the development of natural gas is focused on. Natural gas, a high quality and efficient clean energy, whose carbon dioxide and nitrogen oxide emissions are only one-half and the fifth of the coal, almost zero sulfur dioxide emissions, has been widely used directly as a fuel or producing hundreds of chemicals in various fields. But in recent decades, China's emphasis on economic development and neglect of the energy effectiveness result in a large waste of energy. Therefore, the effective supply of energy, especially effective supply of natural gas, should be put on the agenda.

Since the middle of last century, the development and utilization of natural gas gather speed, the natural gas power represented by the United States, Russia and worldwide natural gas industry in the Middle East, Latin America rapidly emerge. In the world's energy consumption structure, the proportion of natural gas has rapidly increased from 10\% in 1950 to 24\% today, becoming the world's third largest energy [2-3] .from the current development trend, as an environmentally friendly fuel, natural gas will become the chief energy of the 21st century and a catalyst to promote future ecological balance [4]. Owing some technical basis, China's natural gas industry has entered a new rapid development period after entering the 21st century. However, the contradiction between demand increase and limited resources has become increasingly intensified, so how the effective supply of natural gas has become an important research topic.

\section{The influence factors for effective supply of natural gas}

Effective supply of energy is a full range of interactive and sustainable supply type considering energy supply, factor supply and supply efficiency [5], while the effective supply of natural gas can make the energy market develop friendly and make it meet the market demand appropriately. Therefore, it is essential to analyze the influence factors.

The influence factors of the effective supply of natural gas in China are mainly divided into three categories: production conditions, the level of consumer demand and market price. The indicators reflecting the production conditions are: natural gas production, the per capita natural gas production, natural gas reserves. The indicators reflecting consumption level are: consumption intensity of natural gas, growth rate of consumption, per capita consumption of natural gas and total consumption of natural gas. The price of natural gas is in a government-led and unified pricing stage, which does not meet the economic laws of market regulation. And the ex-factory price is far 
below the international trade price, which is an important factor restricting the effective supply of natural gas. However, it is not easy to obtain specific data for factor analysis due to the volatility of natural gas prices in real time. Thus the market price has not been taken into consideration, but it plays an important role for the effective supply of natural gas. In addition, the development of our national economy will naturally boost China's energy development, so the production and consumption elasticity coefficient of natural gas should also be considered. The technical level represented by processing and conversion rate and the trade situation represented by the amount of import and export also reflect the supply level of natural gas to some extent.

\section{Factor analysis of the effective supply of natural gas}

\subsection{The identification of index and method}

Considering the above analysis and the availability of data, natural gas reserves, natural gas production, gas production elasticity coefficient, natural gas consumption elasticity coefficient, natural gas consumption, gas processing and conversion rate and natural gas import and export volume are chosen as variables which affect the effective supply of natural gas. The comprehensive influence factors about effective supply of natural gas can be got by the analysis method in SPSS, and thus to analyze the main influence factors about the effective supply of natural gas. Determine the weight of each influence factor by the results and measure the comprehensive evaluation value by using the weighted average method [6].

\subsection{The sources of data}

The data used in this paper comes from the "China Statistical Yearbook" and "BP statistical review of world energy full report 2012", specific data is in Table 1. We will use A-H to represent these indicators: natural gas reserves, natural gas production elasticity coefficient, energy processing and conversion rate, natural gas production, natural gas import volume, natural gas export volume, energy consumption elasticity coefficient, natural gas consumption.

Table1: Influence factors table of effective supply of natural gas

\begin{tabular}{|c|c|c|c|c|c|c|c|c|}
\hline & & & & & & \multicolumn{3}{|c|}{ Unit: million cubic meters } \\
\hline indicators & A & B & $\mathrm{C}(\%)$ & $\mathrm{D}$ & E & $\mathrm{F}$ & G & $\mathrm{H}$ \\
\hline 2002 & 20169 & 0.52 & 69 & 326.6 & 0 & 32 & 0.66 & 291.8 \\
\hline 2003 & 22288.7 & 1.41 & 69.4 & 350.2 & 0 & 18.7 & 1.53 & 339.1 \\
\hline 2004 & 25292.6 & 1.43 & 70.9 & 414.6 & 0 & 24.4 & 1.6 & 396.7 \\
\hline 2005 & 28185.4 & 0.88 & 71.6 & 493.2 & 0 & 29.7 & 0.93 & 467.6 \\
\hline 2006 & 30009.2 & 0.58 & 71.2 & 585.5 & 9.5 & 29 & 0.76 & 561.4 \\
\hline 2007 & 32123.6 & 0.46 & 70.8 & 692.4 & 40.2 & 26 & 0.59 & 705.2 \\
\hline 2008 & 34049.6 & 0.56 & 71.6 & 803 & 46 & 32.5 & 0.41 & 812.9 \\
\hline 2009 & 37074.2 & 0.59 & 72 & 852.7 & 76.3 & 32.1 & 0.57 & 895.2 \\
\hline 2010 & 37793.2 & 0.78 & 72.8 & 948.5 & 164.7 & 40.3 & 0.58 & 1075.8 \\
\hline 2011 & 40206.4 & 0.76 & 72.3 & 1026.9 & 311.5 & 31.9 & 0.76 & 1305.3 \\
\hline
\end{tabular}

\subsection{The application of factor analysis by SPSS}

In this paper, the original data on the 2002-2011 years influencing effective supply of natural gas is processed by SPSS and the correlation coefficient matrix, common factor variance ratio table, the primary ingredient table, factor loading matrix and factor scores table of the above eight variables are obtained as Table 2-6. As well as the scatter plot of main components is arranged according to the characteristic roots, as shown in Fig.1. 
Table2: Correlation Matrix

Unit: million cubic meters

\begin{tabular}{ccccccccc}
\hline & $\mathrm{A}$ & $\mathrm{B}$ & $\mathrm{C}(\%)$ & $\mathrm{D}$ & $\mathrm{E}$ & $\mathrm{F}$ & $\mathrm{G}$ & $\mathrm{H}$ \\
\hline $\mathrm{A}$ & 1.000 & .409 & .908 & .987 & .782 & .606 & .576 & .962 \\
$\mathrm{~B}$ & .409 & 1.000 & .221 & .440 & .177 & .587 & .949 & .362 \\
$\mathrm{C}(\%)$ & .908 & .221 & 1.000 & .860 & .636 & .644 & .415 & .825 \\
$\mathrm{D}$ & .987 & .440 & .860 & 1.000 & .829 & .655 & .620 & .985 \\
$\mathrm{E}$ & .782 & .177 & .636 & .829 & 1.000 & .499 & .319 & .913 \\
$\mathrm{~F}$ & .606 & .587 & .644 & .655 & .499 & 1.000 & .749 & .619 \\
$\mathrm{G}$ & .576 & .949 & .415 & .620 & .319 & .749 & 1.000 & .539 \\
$\mathrm{H}$ & .962 & .362 & .825 & .985 & .913 & .619 & .539 & 1.000 \\
\hline
\end{tabular}

Table3:Common factor variance ratio

\begin{tabular}{ccc}
\hline & Initial & Extraction \\
\hline A & 1.000 & .953 \\
B & 1.000 & .942 \\
C $(\%)$ & 1.000 & .811 \\
D & 1.000 & .976 \\
E & 1.000 & .804 \\
F & 1.000 & .717 \\
G & 1.000 & .985 \\
H & 1.000 & .976 \\
\hline
\end{tabular}

From Table 2 and Table 3, correlation between various factors is relatively high and information extraction rate of most variables are more than $90 \%$, so it is suitable for factor analysis.

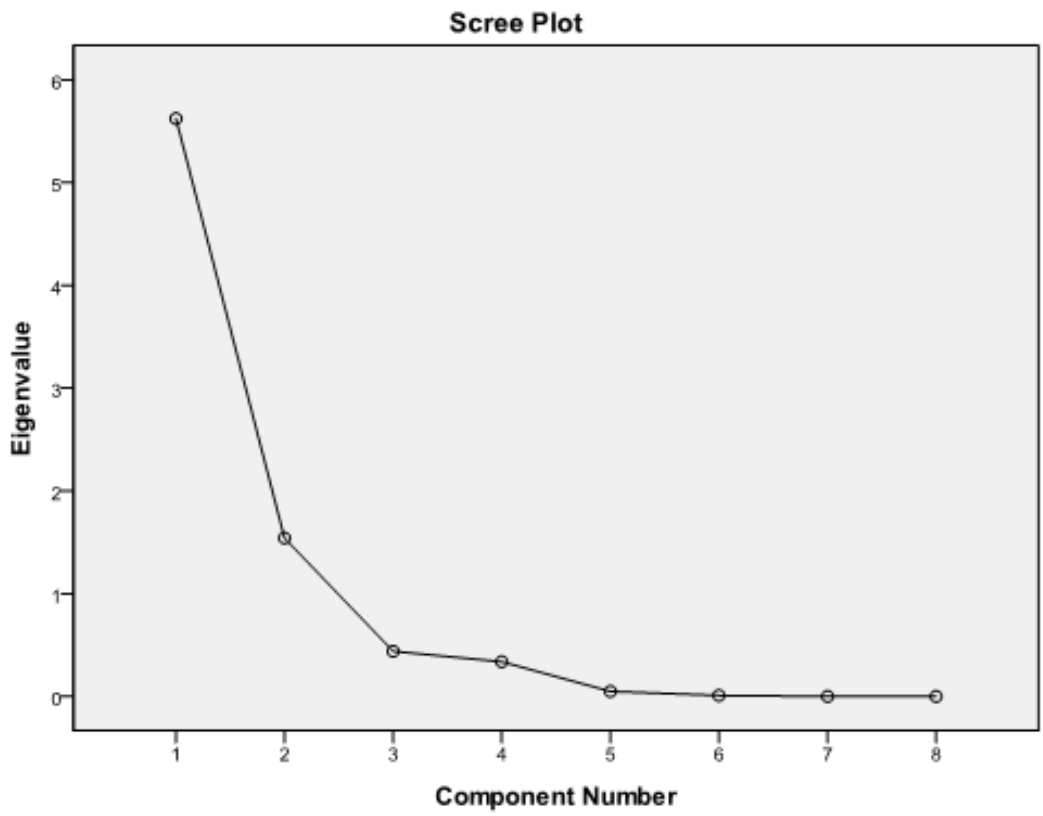

Fig.1: Scatter Plot 
Table4:Main component

\begin{tabular}{|c|c|c|c|c|c|c|}
\hline \multirow{2}{*}{$\begin{array}{c}\text { Compon } \\
\text { ent }\end{array}$} & \multicolumn{3}{|c|}{ Initial Eigen values } & \multicolumn{3}{|c|}{ Extraction Sums of Squared Loadings } \\
\hline & Total & $\begin{array}{c}\% \text { of } \\
\text { Variance }\end{array}$ & $\begin{array}{c}\text { Cumulative } \\
\%\end{array}$ & Total & $\begin{array}{c}\% \text { of } \\
\text { Variance }\end{array}$ & $\begin{array}{c}\text { Cumulativ } \\
\text { e } \%\end{array}$ \\
\hline 1 & 5.622 & 70.280 & 70.280 & 5.622 & 70.280 & 70.280 \\
\hline 2 & 1.541 & 19.263 & 89.543 & 1.541 & 19.263 & 89.543 \\
\hline 3 & .440 & 5.497 & 95.040 & & & \\
\hline 4 & .338 & 4.220 & 99.261 & & & \\
\hline 5 & .049 & .613 & 99.874 & & & \\
\hline 6 & .009 & .115 & 99.989 & & & \\
\hline 7 & .001 & .011 & 100.000 & & & \\
\hline 8 & $\begin{array}{c}1.296 \\
\text { E-5 }\end{array}$ & .000 & 100.000 & & & \\
\hline
\end{tabular}

Fig. 1 and Table 4 show that the cumulative contribution rate of the first two factors reached $89.543 \%$ and only lost $10.457 \%$. Thus the changes of these two factors can behalf of the changes of entire factors influencing the effective supply of natural gas.

Table5:factor loading matrix

\begin{tabular}{ccc}
\hline & 1 & Component \\
& .954 & 2 \\
\hline Natural gas reserves & .574 & -.206 \\
Natural gas production & & .782 \\
elasticity coefficient & .852 & -.293 \\
Energy processing and & .973 & -.168 \\
$\quad$ conversion rate(\%) & .799 & -.407 \\
natural gas production & .788 & .311 \\
Natural gas import volume & .738 & .664 \\
Natural gas export volume & .952 & -.263 \\
$\quad \begin{array}{c}\text { Energy consumption } \\
\text { elasticity coefficient }\end{array}$ & & \\
Natural gas consumption & & \\
\hline
\end{tabular}

From Table 5, common factor F1 has a very large load on natural gas reserves, natural gas production and the total natural gas consumption, so the production conditions and consumer demands play a vital role for efficient supply of natural gas. Common factor F2 has a larger load on gas production and consumption elasticity coefficient. Thus the effective supply of natural gas is closely related to the development of our national economy. 
Table6: Factor analysis table

\begin{tabular}{lcc}
\hline years & F1 & F2 \\
\hline 2002 & -0.85182 & -1.72609 \\
2003 & -1.56899 & 1.07855 \\
2004 & -1.12172 & 1.33467 \\
2005 & -0.36808 & -0.11334 \\
2006 & -0.1244 & -0.61519 \\
2007 & 0.0836 & -0.68486 \\
2008 & 0.55752 & -0.67733 \\
2009 & 0.73189 & -0.18585 \\
2010 & 1.27243 & 0.31554 \\
2011 & 1.38957 & 1.2739 \\
\hline
\end{tabular}

Weighted by factor contribution in Table4, with $\mathrm{F}=0.7028 \mathrm{~F} 1+0.1926 \mathrm{~F} 2$, combined with factor scores in Table 6,get the index of effective supply of natural gas by weighted average method, which is shown in Table 7 and Figure 2.

Table7: the index of effective supply of natural gas in China

\begin{tabular}{lc}
\hline year & the index of effective supply of natural gas \\
\hline 2002 & -0.931 \\
2003 & -0.895 \\
2004 & -0.531 \\
2005 & -0.281 \\
2006 & -0.206 \\
2007 & -0.073 \\
2008 & 0.261 \\
2009 & 0.479 \\
2010 & 0.955 \\
2011 & 1.222 \\
\hline
\end{tabular}

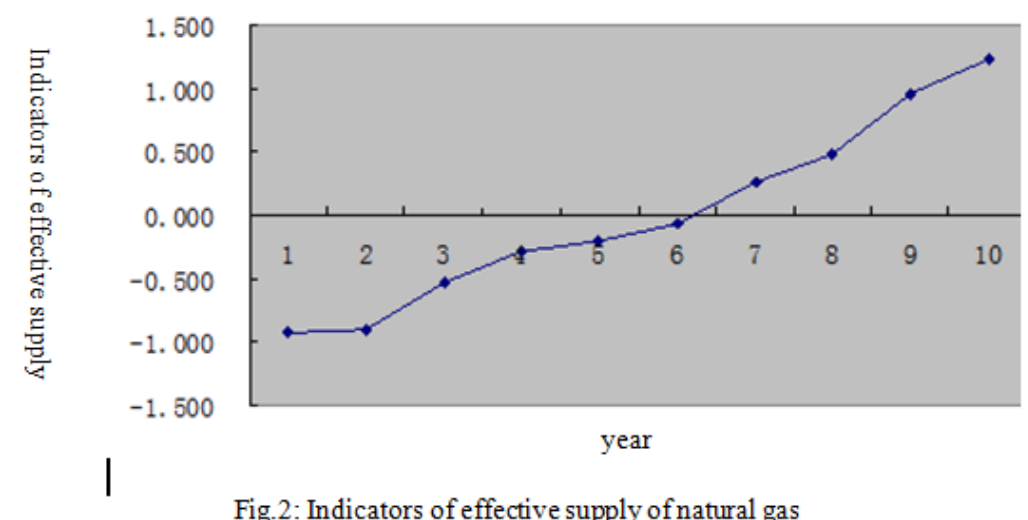

Table7 and Fig. 2 show that the effective supply of natural gas presented a rising trend from 2002 to 2011, which is closely related to the country's rapid development. However, with the increasing demand for resources and limited restrictions, the index of effective supply of natural gas tends to balance or even decrease, so the effective supply of natural gas is a new challenge for our country.

\section{Conclusion}

Based on the above analysis, the main factors affecting the effective supply of natural gas include production capacity, market demand, technical factors, the level of economic development 
and trade status. According to the factor analysis method, production capacity and market demand play the most important role for its effective supply, followed by technical factors, China's economic development and trade situation have a certain degree of influence.

\section{Strategies}

Based on the above conclusion, in order to increase effective supply capacity of natural gas, the strategies are as follows: the key factors should be focused on. By improving detection capability [7] and capital investment to increase production; establishing a market demand-oriented system to expand the effective supply of natural gas. In addition, related factors cannot be ignored; we can improve production technology [8], increase the mutual substitution efficiency between energy, reform natural gas pricing system and other ways to ensure the effective supply sustainability and level of natural gas.

\section{References}

[1] Zhou Yan. Research on Environmental Impact of Regional Energy[D]. Shanghai Normal University.2009

[2] Huang Weihe: West- to- East Gas Transmission Project and Development of China Natural Gas Industry[J]. OGST, 2003, 22 (9) 4- 7.

[3] Qian Bozhang.The Supply and Demand Forecasts of Natural Gas in the World[J]. Natural Gas and Oil. 2006, 24(2):44-48

[4] Kang Yunfeng. Prediction Research on Natural Gas Consumption Based on Projection Pursuit[D]. Southwest Petroleum University.2009

[5] Chen Duanji. Research on Attacking Problem in China's Market Economy[D]. Xiamen University.2013

[6] Xue Weixian, Meng Juan. An Empirical Research on the Phased Assessment of Industrialization in China [J]. Economic Theory and Business Management.2006,(1):19.

[7] Zhang Lifeng. The Research of the Model of Energy Supply and Demand and the Development Countermeasure of China[D]. Capital University of Economics and Business.2006

[8] Cheng Jinhua,Chen Jun,Duan Pingzhong.An Evaluation on the Effective Supply of China's Non-recycled Energy for Past 15 Years[J]. Policy Research.2009,(11):07-14 